\title{
Using 'Paddy Field' Graphic Organiser to Enhance Students' Ability in Expanding and Simplifying Algebraic Expressions
}

\author{
Lim Yi Wei \\ SMK Sanzac, Kota Kinabalu, Malaysia
}

\begin{abstract}
The purpose of this action research was to enhance students' abilities in expanding and simplifying algebraic expressions. A total of 26 students from 3 Anggerik (9th Grade) SMK SANZAC, Malaysia, were involved in this action research. Based on the analysis of their marks from the previous test and mid-year examination, they were unable to solve algebraic expressions, even though they had learnt them since Form $1\left(7^{\text {th }}\right.$ Grade). However, expanding and simplifying algebraic expressions are fundamental to solving mathematics problems, with approximately $46 \%$ of lower form mathematic topics requiring these skills. Hence, the "Paddy Field" method was introduced to help students expand and simplify algebraic expressions. Post-test results showed a significant improvement in students' abilities to expand and simplify algebraic expressions.
\end{abstract}

Keywords: algebra, learning difficulties, expanding and simplifying algebraic expressions.

\section{Introduction}

The problem occurred in my classroom initiated this research. One of the challenges that the researcher encountered in my mathematics class was making students understand the expansion and simplification of algebraic expressions. Their low achievement results in this topic have proven that I failed to make them understand how to expand and simplify algebraic expressions with my conventional teaching method as a teacher. This situation seems to persist across the grades. Many of them are still struggling with basic algebraic expression questions ever since form 1 ( $7^{\text {th }}$ Grade). They claimed that algebra was the toughest topic in mathematics. I felt worried, especially for my form 3 ( $9^{\text {th }}$ Grade) students because they will sit for the year-end form 3 assessment. This has motivated the researcher to look into the problem to understand their learning difficulties in this topic.

From students' answers, it is found out that the main difficulties encountered while expanding and simplifying algebraic expressions were the lack of conceptual understanding and poor computational procedures. These common mistakes included equal sign errors, negative sign errors, and bracket expansion errors, as shown in Table 1. This is similar to what has been identified by Jupri et al. (2014).

In school, algebra expression is the macro concept that has a great influence in developing other micro mathematics concepts like functions, quadratics, arithmetic sequences, and more. It is also an important foundation to prepare students for mastering other STEM subjects. If these common mistakes persist without intervention, they will hinder students' ability to solve even simple calculations. That is why enhancing students' abilities to expand and simplify algebraic expressions are so important. 


\section{Table 1}

Sample of Students Works with Conception and Procedural Errors

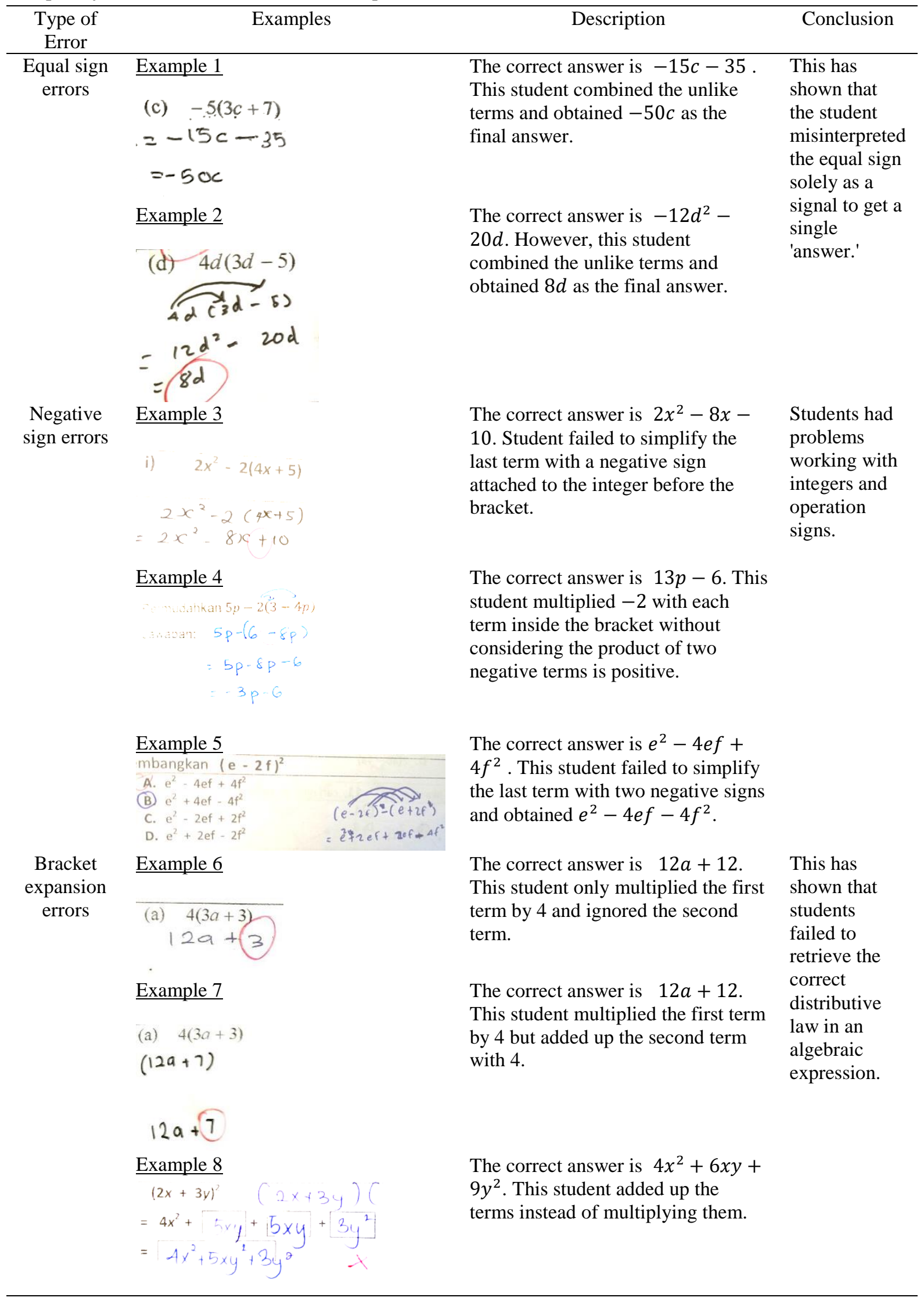


Previous studies have identified that students' difficulties with early algebra are most prone to happen during the transition from arithmetic to algebra (Cai, $\mathrm{Ng}, \&$ Moyer, 2011; Welder, 2012). One of these difficulties is bracket usage. In arithmetic, brackets are used to show students which operation to perform first (Welder, 2012). For instance, the bracket in 18 - (9-10) means to carry out the operation 9-10 inside the bracket first. However, students need to have much more flexible thinking in algebra because the bracket indicates the priority of operation and multiplication (Welder, 2012). For instance, the bracket in 4(a+5) means multiplying both terms in the bracket by 4 . Oftentimes, students are confused and misapply the first rule into expanding and simplifying the algebraic expression.

Another difficulty in algebra is the misconception in the equal sign (Hewitt, 2012). According to Strand \& Mills (2014), there are different meanings of the equal sign. An equal sign can be viewed as an operation symbol, which means 'to do something' or 'find the total' or 'the answer comes next' (Powell, 2012; Strand \& Mills, 2014). However, many students misinterpreted the equal sign solely as a signal to get a single 'answer.' This happened because, throughout primary school arithmetic learning, students are repeatedly exposed to standard equations with one answer $8+4=12$ or $8-4=4$ (Powell, 2012). Hence, when an algebraic expression such as $6+a$ is given to them, they tend to compress it down into a single entity with no operation shows, such as 6a (Hewitt, 2012).

The equal sign can also be viewed as a relational symbol which keeps two sides of an equation balanced and equivalent (Welder, 2012). This relational understanding is critical in learning algebra. However, most of the teacher manuals and student textbooks do not provide enough opportunities to foster a relational understanding of the equal sign (McNeil et al., 2006).

This research focused on improving students' ability in expanding and simplifying algebraic expressions. Expanding and simplifying algebraic expressions are the fundamental parts of solving mathematics problems, yet so many students failed to do so and lost interest in mathematics. Previous studies (Booth, Barbieri, Eyer, \& Paré-Blagoev, 2014; Lim, 2010; Ottmar \& Landy, 2017) had shown that the concept of expanding and simplifying an algebraic expression was very abstract for students to visualise concretely. Students who have reached the middle grades and are still experiencing difficulty with mathematical concepts are often provided with rote approaches only, keeping them from gaining the conceptual frameworks necessary for success with algebraic tasks(Dacey \& Gartland, 2019). One of the interventions to deal with these students' difficulty is by supporting it with digital manipulative and helping students expand brackets (Jupri, Drijvers, \& van den HeuvelPanhuizen, 2015).

In this study, the researcher did not use ICT based activity instead of hands-on activity. To help students visualise and organise the computational procedures of expanding and simplifying algebraic expressions, a graphic organiser, "The Paddy Field" is introduced to them. Ives \& Hoy (2003) have pointed out that when students are allowed to expand and simplify the algebraic expression visually and systematically, they are more likely to succeed in algebraic tasks.

This study aims to enhance students' ability in expanding and simplifying algebraic expressions. This study tried to support the student to expand and simplify one bracket 
algebraic expressions, expand and simplify two brackets algebraic expressions, and ensure hands-on learning activities in expanding and simplifying algebraic expressions.

\section{Methods}

This is a classroom action research study. A pre-test was given to students before the intervention lesson to determine the target group's baseline knowledge in expanding and simplifying algebraic expressions. It consisted of 10 questions on these mathematics skills. Each question was designed to measure various operations of simplifying and expanding in algebraic expressions. For instance, item one was used to see if students could expand and simplify one bracket algebraic expression with unlike terms. While item three was used to see if students could expand and simplify one bracket algebraic expression with a negative premultiplier. Table 2 displays the questions which students were asked in the pre-test.

Table 2

Pre-test Questions

\begin{tabular}{|c|c|c|}
\hline Question Number & Question & Question Rationale \\
\hline 1 & $6(3+4 w)$ & $\begin{array}{l}\text { To test students understanding of multiplying one bracket } \\
\text { algebraic expression with unlike terms and positive sign }\end{array}$ \\
\hline 2 & $3 r(r-2 s)$ & $\begin{array}{l}\text { To test students understanding of multiplying one bracket } \\
\text { algebraic expression with unlike terms and a negative sign }\end{array}$ \\
\hline 3 & $-5 b(a+3)$ & $\begin{array}{l}\text { To test students understanding of multiplying one bracket } \\
\text { algebraic expression with negative pre-multiplier and a } \\
\text { positive integer }\end{array}$ \\
\hline 4 & $-2(\mathrm{pr}-3)$ & $\begin{array}{c}\text { To test students understanding of multiplying one bracket } \\
\text { algebraic expression with negative pre-multiplier and } \\
\text { negative integer }\end{array}$ \\
\hline 5 & $(a+1)(a+2)$ & $\begin{array}{l}\text { To test students understanding of multiplying two brackets } \\
\text { algebraic expression with only positive integers }\end{array}$ \\
\hline 6 & $(x-5)(x+4)$ & $\begin{array}{l}\text { To test students understanding of multiplying two brackets } \\
\text { algebraic expression with positive and negative integers }\end{array}$ \\
\hline 7 & $(3 p-2)(4 p-1)$ & $\begin{array}{l}\text { To test students understanding of multiplying two brackets } \\
\text { algebraic expression with two negative integers }\end{array}$ \\
\hline 8 & $(r-3 s)^{2}$ & $\begin{array}{c}\text { To test students understanding of multiplying single bracket } \\
\text { algebraic expression with a square }\end{array}$ \\
\hline 9 & $3 x^{2}-4(2 x+3)$ & $\begin{array}{c}\text { To test students understanding of solving one bracket } \\
\text { complex algebraic expression }\end{array}$ \\
\hline 10 & $(b-1)^{2}-9$ & $\begin{array}{l}\text { To test students understanding of solving two brackets } \\
\text { bracket complex algebraic expression }\end{array}$ \\
\hline
\end{tabular}

The rationale for using these questions was to fulfil the requirement of the secondary school mathematics curriculum and assessment standard offered by the Ministry of Malaysia Education (2016). Besides, these items were discussed with other mathematics teachers to fulfil the instrument's validity. Similar questions were reshuffled and were used as post-test at the end of the research study for comparison and analysis purposes. Students have to complete each test within thirty minutes.

The target group consists of 26 students from 3 Anggerik. The selection of respondents was based on the items' analysis of their mid-year mathematics exam paper. I discovered that this group of students have difficulties in expanding and simplifying algebraic expressions.

Based on a 2019 mid-year mathematics examination paper, it was obvious that most of my students struggled with algebraic expressions. This was reflected in Table 3 below, with the 
second column from the left showing the percentage of students who did not get the correct answer. The third column shows the percentage of students who left the question blank without answering. Looking at their results, I could conclude that they failed because I failed to make them understand how to expand and simplify algebraic expressions with my conventional teaching method.

Table 3

Analysis Items of 2019 Form 3 Anggerik Mid-year Mathematics Exam Paper

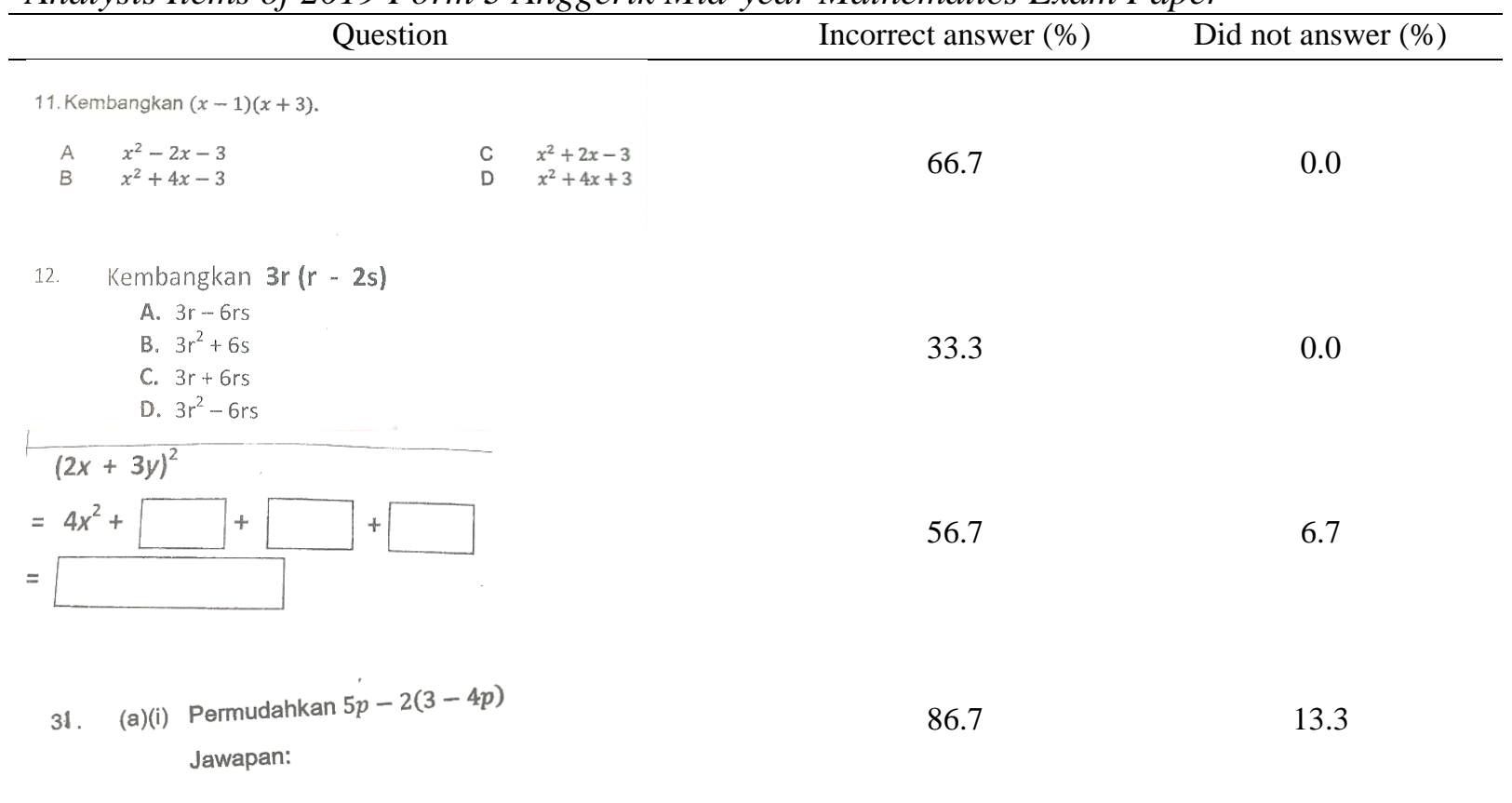

The data was analysed using descriptive statistics. My limitation was that the post-test was only conducted once due to time factors. It can be further enhanced with another post-testing after a period of time to see whether students can still apply this method.

\section{Results and Discussion}

\section{Implementation of "Paddy Field"}

The "Paddy Field" is adopted from the grid method to clear students' confusion in applying the conventional FOIL (First, Outer, Inner, Last). It consists of 4 square grids which look like the Chinese word “田” (tian) which means paddy field in English. The "Paddy Field" helps students to find the product of algebraic expressions in a tidier and more organised way. 


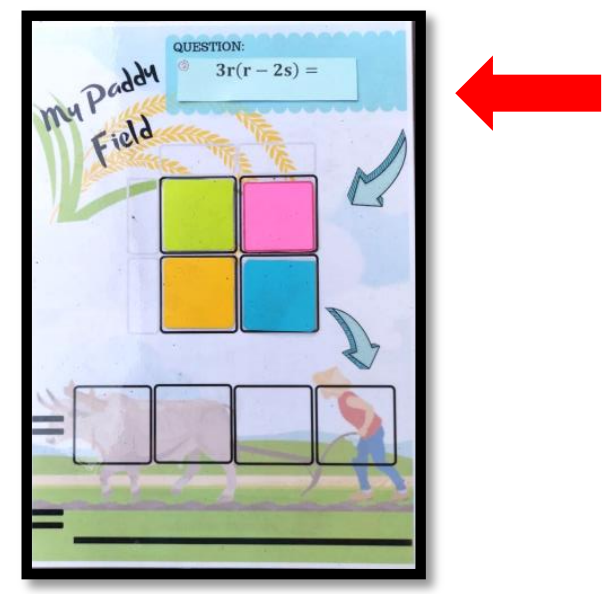

Figure 1. An example with one binomial.

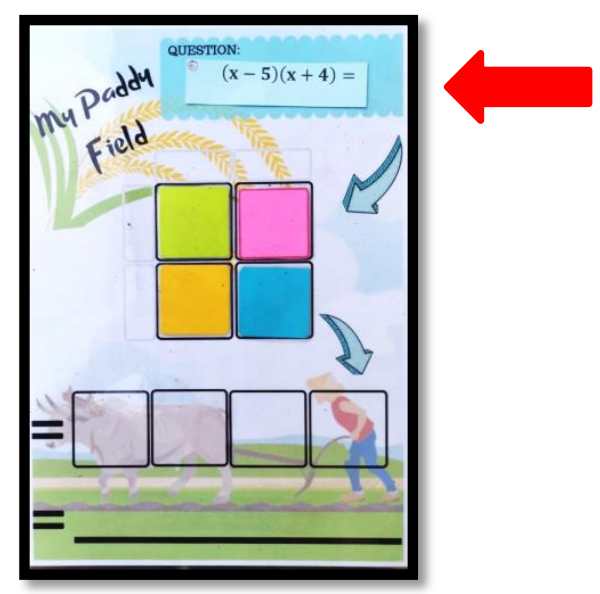

Figure 2. An example of two binomials.

Firstly, each of the students is given one set of "Paddy Field". There are two types of the set, algebraic expression with one binomial as in Figure 1 and algebraic expression with two binomials as in Figure 2. They are asked to put the algebraic expression question in the blue box in the right upper corner.

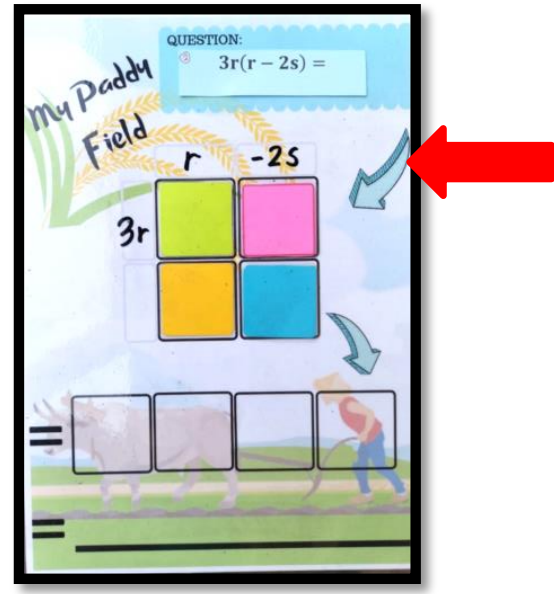

Figure 3. An example with one binomial. binomials

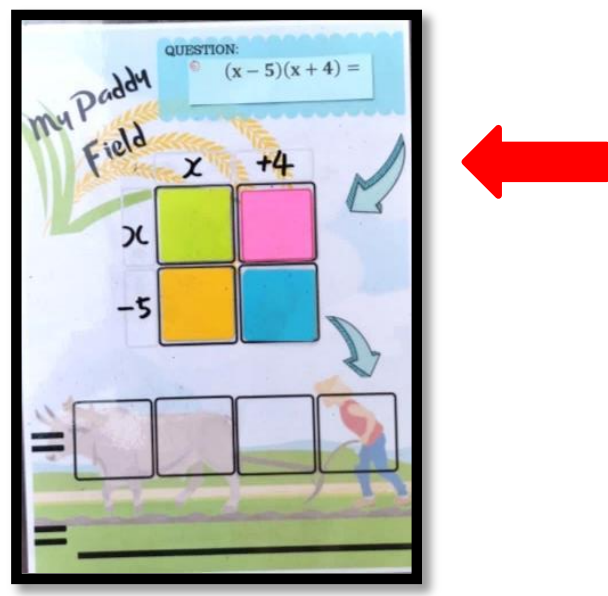

Figure 4. An example with two

Then they have to write each term of the algebraic expression in the grey boxes beside "田". If the question consists of only 1 term outside the bracket, they have to write that term in the first vertical grey box and the other two terms inside the bracket by the two horizontal grey boxes (Figure 3).

If the question consists of two brackets, they have to write each term of the first bracket in the vertical grey boxes and write each term of the second bracket in the horizontal grey boxes (Figure 4). However, students are reminded it does not matter whether one puts the terms of the first bracket in the vertical grey boxes first or horizontal grey boxes first. 


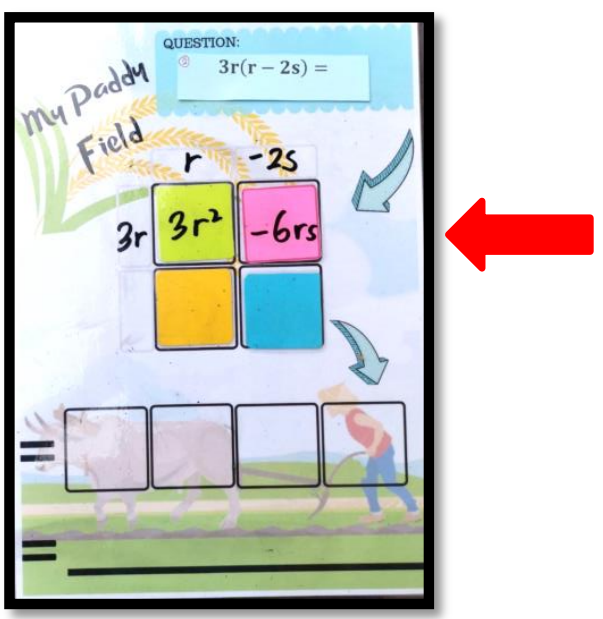

Figure 5. An example with one binomial.

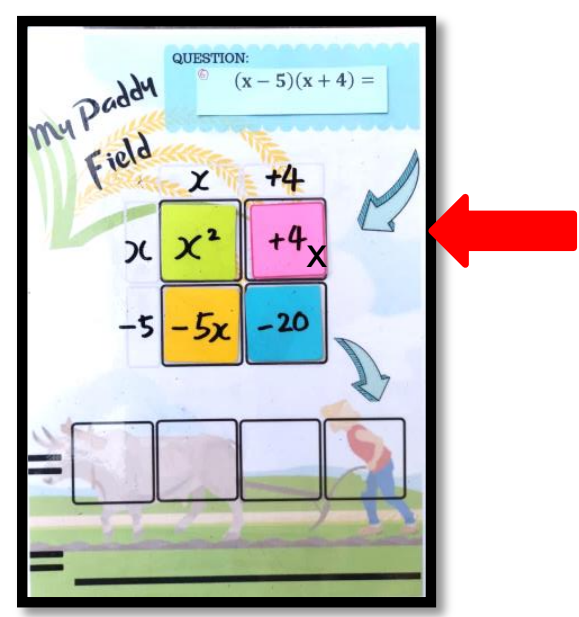

Figure 6. An example of two binomials.

After that, they have to write down the product of the numbers in its row and column. For instance, in Figure 5, $3 r$ in its column and $r$ in its row. The product is $3 r$ multiplied by $r$ which is $3 r^{2}$. Students have to be reminded that they will get the area of each partition of "The Paddy Field". They have to multiply the terms and not to sum up the terms from each side.

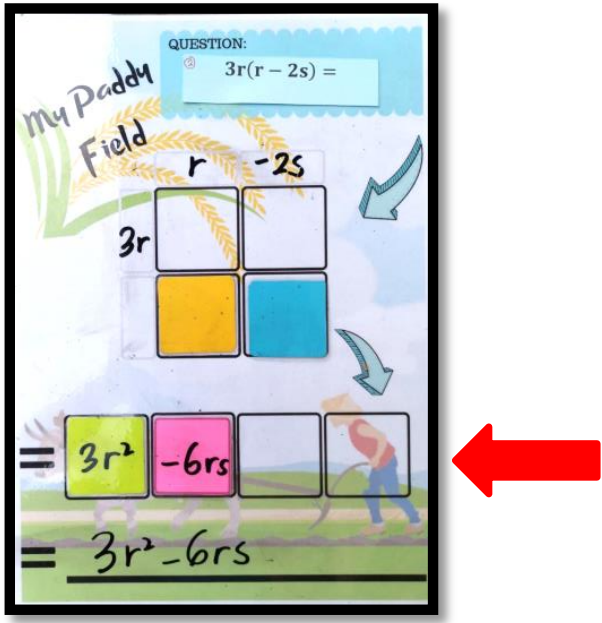

Figure 7. An example with one binomial.

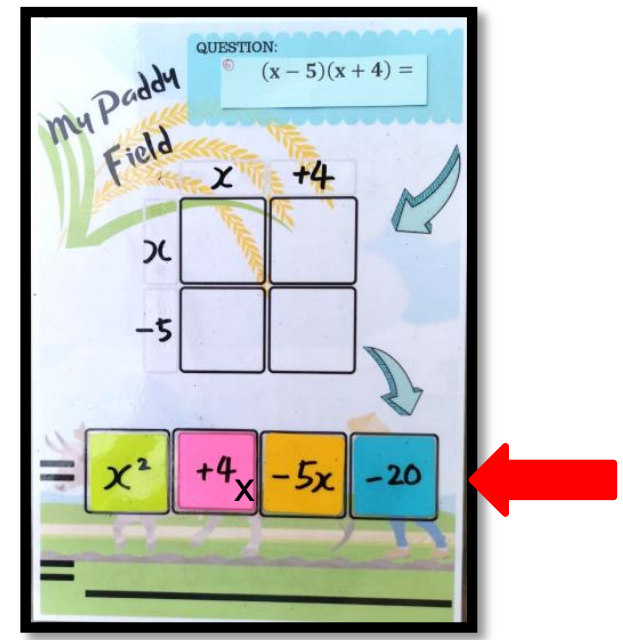

Figure 8. An example of two binomials.

Students are told to move the colourful cards from "⿴囗十 " and arrange them from the term with the largest exponent to the constant on the row of boxes provided as illustrated in Figure 7 and Figure 8. 


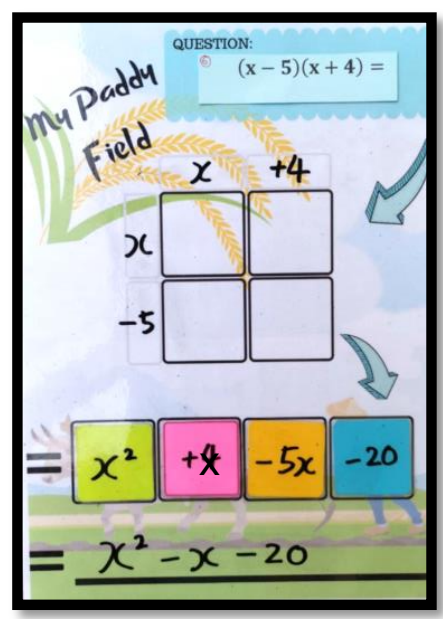

Figure 9. An example of two binomials.

Lastly, students have to simplify the algebraic expression by combining the like terms. Then they have to write the algebraic expression in the simplest form.

\section{Observation}

During the activity, students seemed to be more confident in solving the algebraic expression questions. When I asked them how they felt about this method, they told me this method was easier to use than the FOIL method.

Teacher : How do you feel about this method?

Student : It's easy. I like it!

Teacher : which one do you prefer? The FOIL method or the Paddy Field method?

Student : Definitely this Paddy Field method.

Teacher : Why not FOIL method?

Student : It's very confusing for me, especially the arrows. I get lost most of the time and get the wrong answer.

Teacher : What is the thing that you like about the Paddy Field method?

Student : I can see the steps more clearly with the boxes provided in the Paddy Field method.

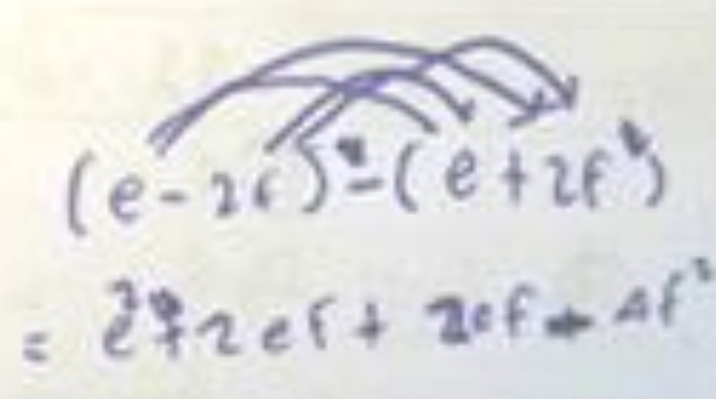

Figure 10. An example of the confusion of a student A using the FOIL method. 
They claimed that the FOIL method was confusing. Most of the time, they get lost while halfway through expanding the algebraic expressions. They claimed that this method actually guided them well to expand every term in the boxes provided.

Through observation, I found that student A, who did not answer most of the pre-test questions, was busy solving the given algebraic expressions questions using "The Paddy Field" graphic organiser. I was glad to see he could expand and simplify algebraic expressions. Meanwhile, he still made some negative sign errors and operation errors while working on those given questions. I believe this can be overcome with more practice and guidance.

Other students seemed to immerse themselves in the activity too. I noticed that they could do well in expanding algebraic expressions. Their problems were similar to student A, which were negative sign errors. They seemed to forget to change the sign while multiplying two negative terms. This is in-line with the study by Booth, Barbieri, Eyer \& Blagoev (2014). It turned out that in the classroom, it becomes a common mistake. Another common error that students made was forgetting to put the variable in the final answer. This mistake also can be found in Lim (2010)'s research. These struggles can be improved with more practice and guidance, as they were not familiar with writing the final answer with variables.

\section{Post-test}

During the post-test, students used "The Paddy Field" graphic organiser in answering posttest questions. In comparison between the pre and post-test results in Table 4, we can see a great improvement in every respondent's ability to expand and simplify algebraic expressions. Three students from no correct answer in the pre-test managed to score full mark in the post-test.

Table 4

Comparison of Students' Scores in the Pre-test and Post-test

\begin{tabular}{lr}
\hline Min Improvement & 3 \\
\hline Max Improvement & 10 \\
Average improvement & 5,33 \\
\hline
\end{tabular}

From table 4, it is observable that all students improved the numbers of correct answers. None of the students received less correct answers than their pre-test scores.

Table 5

Comparison of Students' Correct Responses in the Pre-test and Post-test

\begin{tabular}{|c|c|c|c|c|c|c|c|}
\hline \multirow[b]{2}{*}{$\begin{array}{c}\text { Algebraic } \\
\text { Expressions } \\
\text { Skills }\end{array}$} & \multicolumn{4}{|c|}{ Pre-Test } & \multicolumn{2}{|c|}{ Post-Test } & \multirow[b]{2}{*}{$\begin{array}{c}\text { Changes in } \\
\text { the } \\
\text { average \% } \\
(+/-)\end{array}$} \\
\hline & Items & $\begin{array}{l}\text { No. of } \\
\text { items }\end{array}$ & $\begin{array}{c}\text { Average } \\
\text { (\%) of } \\
\text { students } \\
\text { with } \\
\text { correct } \\
\text { responses }\end{array}$ & Items & $\begin{array}{l}\text { No. of } \\
\text { items }\end{array}$ & $\begin{array}{c}\text { Average } \\
(\%) \text { of } \\
\text { students } \\
\text { with } \\
\text { correct } \\
\text { responses }\end{array}$ & \\
\hline $\begin{array}{l}\text { Expand one } \\
\text { bracket } \\
\text { algebraic }\end{array}$ & $1,2,3,4,9$ & 5 & 70.77 & $2,4,7,8,9$ & 5 & 90.00 & +19.23 \\
\hline
\end{tabular}




\begin{tabular}{|c|c|c|c|c|c|c|c|}
\hline & & & & & & & \\
\hline $\begin{array}{l}\text { expressions } \\
\text { Simplify one } \\
\text { bracket } \\
\text { algebraic } \\
\text { expressions }\end{array}$ & $1,2,3,4,9$ & 5 & 55.38 & $2,4,7,8,9$ & 5 & 84.62 & +29.24 \\
\hline $\begin{array}{l}\text { Expand two } \\
\text { brackets } \\
\text { algebraic } \\
\text { expressions }\end{array}$ & $5,6,7,8,10$ & 5 & 31.54 & $1,3,5,6,10$ & 5 & 92.30 & +60.76 \\
\hline $\begin{array}{l}\text { Simplify two } \\
\text { brackets } \\
\text { algebraic } \\
\text { expressions }\end{array}$ & $5,6,7,8,10$ & 5 & 10.77 & $1,3,5,6,10$ & 5 & 80.77 & +70.00 \\
\hline
\end{tabular}

Results from Table 5 indicated that students' skill in simplifying two brackets algebraic expressions improved the most, from $10.77 \%$ to $70.00 \%$ out of four algebraic expression skills. Followed by expanding two brackets algebraic expressions, from $31.54 \%$ to $92.30 \%$. Most students did not have a problem expanding one bracket algebraic expressions before and after the intervention, as reflected in high scores in both pre-test and post-test scores.

Students exposed to the "Paddy Field" graphic organiser could expand and simplify algebraic expressions more confidently. Compared to the conventional FOIL method, this grid method, which was integrated with a hands-on activity, is not only fun to learn, but it helped students to expand and simplify the algebraic expression in a tidier and more systematic way. Furthermore, "Paddy Field" graphic organiser managed to attract students' attention and increased their involvement in its graphic design that closely resembles daily life.

When I saw that my weak students could solve algebraic expressions questions with "The Paddy Field" graphic organiser, I realised how important an effective graphic organiser is for improving algebra knowledge in students. Future research should look into graphic organisers to help students solve algebra-related topics such as linear equations and inequalities, quadratics and polynomials, graphing lines and slope, functions, and many more. Before doing so, I will conduct another test in the next cycle to see whether students can apply this grid method without the "Paddy Field" graphic organiser in answering the algebraic expression questions. I will also upgrade the present "Paddy Field" graphic organiser to a magnetic version so that the four coloured cards will glide smoothly and firmly on the graphic organiser.

\section{Conclusion}

The overall findings of this action research have shown a positive response to its objectives. It has shown that using an appropriately designed graphic organiser to teach mathematical skills truly helps students be more successful in mathematics. However, it occurred in my classroom only, and its generalisability is limited. Furthermore, teachers play an important role in thinking of ways suitable for their students' learning. Finding the proper and suitable for students is crucial. It needs extra work for teachers to develop competencies to design/ creates suitable activities for students. 


\section{Acknowledgement}

I would like to express my sincere gratitude to previous Excellent Principal JUSA C of SMK SANZAC, Dr Shirley Tay Siew Hong, for her patient guidance, valuable comments and constant encouragement throughout this action research.

I would also like to thank Mr Wahid Yunianto, mathematics specialist, and his team from SEAMEO Regional Centre for QITEP in Mathematics for the valuable comments, proofreading and layout editing.

\section{References}

Booth, J. L., Barbieri, C., Eyer, F., \& Paré-Blagoev, E. J. (2014). Persistent and pernicious errors in algebraic problem-solving. Journal of Problem Solving, 7(1). https://doi.org/10.7771/1932-6246.1161

Cai, J., Ng, S. F., \& Moyer, J. C. (2011). Developing Students' Algebraic Thinking in Earlier Grades: Lessons from China and Singapore. https://doi.org/10.1007/978-3-642-177354_3

Dacey, L., \& Gartland, K. (2019). Math for all: Differentiating instruction, grades 6-8 (J. Ann Cross, ed.). Sausalito: California: Scholastic Inc.

Hewitt, D. (2012). Young students learning formal algebraic notation and solving linear equations: Are commonly experienced difficulties avoidable? Educational Studies in Mathematics, 81(2). https://doi.org/10.1007/s10649-012-9394-x

Ives, B., \& Hoy, C. (2003). Graphic Organisers Applied to Higher-Level Secondary Mathematics. Learning Disabilities Research and Practice, 18(1). https://doi.org/10.1111/1540-5826.00056

Jupri, A., Drijvers, P., \& van den Heuvel-Panhuizen, M. (2014). Difficulties in initial algebra learning in Indonesia. Mathematics Education Research Journal, 26(4). https://doi.org/10.1007/s13394-013-0097-0

Jupri, A., Drijvers, P., \& van den Heuvel-Panhuizen, M. (2015). Improving Grade 7 Students' Achievement in Initial Algebra Through a Technology-Based Intervention. Digital Experiences in Mathematics Education, 1(1). https://doi.org/10.1007/s40751-015-00042

Lim, K. S. (2010). An Error Analysis of Form 2 (Grade 7) Students in Simplifying Algebraic Expressions: A Descriptive Study. Electronic Journal of Research in Educational Psychology, 8(1).

McNeil, N. M., Grandau, L., Knuth, E. J., Alibali, M. W., Stephens, A. C., Hattikudur, S., \& Krill, D. E. (2006). Middle-school students' understanding of the equal sign: The books they read can't help. Cognition and Instruction, 24(3). https://doi.org/10.1207/s1532690xci2403_3 
Ministry of Education Malaysia. (2016). Kurikulum standard sekolah menengah: Standard kurikulum dan pentaksiran matematik tingkatan 2. Putrajaya, Malaysia.

Ottmar, E., \& Landy, D. (2017). Concreteness Fading of Algebraic Instruction: Effects on Learning. Journal of the Learning Sciences, 26(1). https://doi.org/10.1080/10508406.2016.1250212

Powell, S. R. (2012). Equations and the equal sign in elementary mathematics textbooks. Elementary School Journal, 112(4). https://doi.org/10.1086/665009

Strand, K., \& Mills, B. (2014). Mathematical content knowledge for teaching elementary mathematics: A focus on algebra. Mathematics Enthusiast, 11(2).

Welder, R. M. (2012). Improving Algebra Preparation: Implications from Research on Student Misconceptions and Difficulties. School Science and Mathematics, 112(4). https://doi.org/10.1111/j.1949-8594.2012.00136.x 